\title{
Urinary Cyclic AMP Analyzed as a Function of the Serum Calcium and Parathyroid Hormone in the Differential Diagnosis of Hypercalcemia
}

\author{
James W. Shaw, Susan B. Oldham, Leonard Rosoff, John E. Bethune, \\ and Marshal P. Fichman \\ From the Departments of Medicine and Surgery, University of Southern California School of Medicine \\ and the Los Angeles County/University of Southern California Medical Center, Los Angeles, California \\ 90033
}

\begin{abstract}
A B S T RACT Urinary cyclic AMP (UcAMP) appropriate for the serum calcium concentration was determined in normal subjects during the base-line state and during alteration in their serum calcium concentrations by saline and calcium infusions. This was compared to the UcAMP in 76 patients with hypercalcemia and 5 patients with hypocalcemia. In 54 of 56 patients with primary hyperparathyroidism, the UcAMP was inappropriately high for their serum calcium concentration, the 2 exceptions having renal failure. In four patients with vitamin D intoxication, sarcoidosis, milkalkali syndrome, and thiazide-induced hypercalcemia and in five patients with hypocalcemia due to hypoparathyroidism, the UcAMP was appropriately low for their serum calcium concentration. In 16 patients with nonparathyroid neoplasms, 10 had UcAMP levels that were inappropriately high suggesting ectopic parathyroid hormone (PTH)-mediated hypercalcemia and 6 had UcAMP levels that were appropriately low suggesting that their hypercalcemia was due to osteolytic factors other than PTH. Correlations between UcAMP, serum calcium concentration, and carboxyl-terminal immunoreactive PTH suggest that random UcAMP is a sensitive accurate reflection of circulating biologically active PTH.

If there is adequate renal function (serum creatinine concentration less than $2.0 \mathrm{mg} / \mathrm{dl}$ ), a random UcAMP expressed as $\mu \mathrm{mol} / \mathrm{g}$ creatinine and analyzed as a function of the serum calcium concentration completely separates patients with PTH and non-PTHmediated hypercalcemia.
\end{abstract}

Presented in part at the National Meeting of the American Federation for Clinical Research, Atlantic City, N. J., 5 May, 1974.

Received for publication 13 October 1975 and in revised form 8 September 1976.

\section{INTRODUCTION}

Since Kaminsky et al. (1) showed that from one-third to one-half of urinary cyclic AMP (UcAMP) ${ }^{1}$ is generated in the kidney under the control of parathyroid hormone (PTH), several somewhat conflicting studies (2-4) have been reported evaluating UcAMP in the differential diagnosis of hypercalcemia. Murad and Pak (2), expressing UcAMP as micromoles per gram of creatinine per $24 \mathrm{~h}$, found elevations in 14 of 15 patients with primary hyperparathyroidism ( $\left.1^{\circ} \mathrm{HPT}\right)$ but found high normal levels in 3 patients with neoplasms metastatic to bone. Dohan et al. (3), expressing UcAMP as micromoles per $24 \mathrm{~h}$, found no significant difference between normal subjects and 16 patients with $1^{\circ} \mathrm{HPT}$, but found normal to low levels in 12 patients with neoplasms with and without evidence of bone metastasis. Neelon et al. (4) noted results similar to both of the above studies, but were able to obtain a $90 \%$ separation between normal subjects and 5 patients with neoplasms metastatic to bone from 24 patients with $1^{\circ} \mathrm{HPT}$ when they calculated a discriminate function using UcAMP expressed both as a function of the urine creatinine and as total excretion $(3.37 \mu \mathrm{mol} / \mathrm{g}$ creatinine per $24 \mathrm{~h}-\mu \mathrm{mol} / 24 \mathrm{~h}$ ).

In this study, UcAMP was measured in normal subjects and a large number of hypercalcemic patients and was correlated with the serum concentrations of calcium and immunoreactive PTH (iPTH) in an attempt to improve the diagnostic accuracy of UcAMP deter-

\footnotetext{
${ }^{1}$ Abbreviations used in this paper: C-terminal; carboxyl terminal; $1^{\circ} \mathrm{HPT}$, primary hyperparathyroidism; iPTH, immunoreactive parathyroid hormone; $\mathrm{N}$-terminal, amino terminal; ng eq, nanogram equivalents; $\mathrm{PTH}$, parathyroid hormone; UcAMP, urinary cyclic $3^{\prime} 5^{\prime}$-adenosine monophosphate.
} 
minations in the differential diagnosis of hypercalcemia. We also evaluated circadian variation and $1-h$ vs. 24-h urine collections in normal subjects and in patients with $1^{\circ} \mathrm{HPT}$.

\section{METHODS}

Clinical data. Subjects studied included 41 normocalcemia controls, 76 patients with hypercalcemia, and 5 patients with hypocalcemia. The 41 controls were all normal healthy adults ranging in age from 21 to $55 \mathrm{yr}(29$ men and 12 women). All had normal renal function, as assessed by serum creatinine concentrations of less than $1.3 \mathrm{mg} / \mathrm{dl}$. None had any history of renal stones. The 76 hypercalcemic patients included 56 with $1^{\circ} \mathrm{HPT}, 16$ with nonparathyroid neoplasms, and 4 others with vitamin $\mathrm{D}$ intoxication, sarcoidosis, milk-alkali syndrome, and thiazide-induced hypercalcemia. The five hypocalcemic patients had either pseudo-, idiopathic, or surgical hypoparathyroidism.

The 56 patients with $1^{\circ} \mathrm{HPT}$ were all evaluated by history, physical examination, and conventional laboratory tests to rule out other causes of hypercalcemia. Most were confirmed by surgery (39 adenomas, 4 hyperplasia, and 1 metastatic parathyroid carcinoma). The others had an inappropriately elevated concentration of serum iPTH. Their ages ranged from 20 to $87 \mathrm{yr}$ (21 men and 35 women). Serum calcium concentrations in these patients ranged from 10.6 to 17.0 $\mathrm{mg} / \mathrm{dl}$ with a mean $\pm \mathrm{SE}$ of $12.19 \pm 0.19$. Serum creatinine concentrations were less than $2.0 \mathrm{mg} / \mathrm{dl}$ in all but two patients. 24-h creatinine clearances in 31 of these patients ranged from 24 to $123 \mathrm{ml} / \mathrm{min}$ with a mean $\pm \mathrm{SE}$ of $67 \pm 5$. Two patients had more advanced chronic renal failure with serum creatinine concentrations of 4.4 and $5.3 \mathrm{mg} / \mathrm{dl}$, respectively.

16 patients had nonparathyroid neoplasms, all of which were proven by biopsy. The presence or absence of bone metastasis was determined by a complete radiologic skeletal survey and (or) by a Tc-99m pyrophosphate bone scan. The patients' ages ranged from 44 to $77 \mathrm{yr}$ (eight men and eight women). Serum calcium concentrations in these patients ranged from 11.4 to $17.4 \mathrm{mg} / \mathrm{dl}$ with a mean $\pm \mathrm{SE}$ of 13.22 \pm 0.43 . Serum creatinine concentrations were less than 2.0 $\mathrm{mg} / \mathrm{dl}$ in all these patients.

The serum calcium concentrations in the four other hypercalcemic patients with vitamin D intoxication, sarcoidosis, milk-alkali syndrome, and thiazide-induced hypercalcemia ranged from 10.7 to $12.0 \mathrm{mg} / \mathrm{dl}$ with a mean $\pm \mathrm{SE}$ of 11.10 \pm 0.30 . Their ages ranged from 18 to $46 \mathrm{yr}$ (two men and two women). Serum creatinine concentrations were normal in three of the four, the exception being the patient with milkalkali syndrome in whom the serum creatinine concentration was $1.9^{\prime} \mathrm{mg} / \mathrm{dl}$. Serum calcium concentrations in the five hypoparathyroid patients ranged from 6.2 to $8.4 \mathrm{mg} / \mathrm{dl}$ with a mean $\pm S E$ of $7.40 \pm 0.35$. Their ages ranged from 20 to $66 \mathrm{yr}$ (two men and three women). Serum creatinine concentrations in these patients were all normal.

Protocols. These studies were performed at the Los Angeles County/University of Southern California Medical Center with the patients' informed consent. All subjects were on a random diet and unrestricted activity. None of the hypercalcemic patients were receiving any treatment to lower their serum calcium concentrations at the time they were studied. A 1-h and(or) a 24-h timed collection of urine was obtained from each subject. The 1-h collections were obtained at random times during the daylight hours $(0800-$ $1800 \mathrm{~h}$ ). Aliquots of freshly voided urine specimens were frozen within $1 \mathrm{~h}$ after collection for later determination of creatinine and cAMP. Blood was drawn at the end of the collection periods and allowed to clot at room temperature for $30 \mathrm{~min}$, and then aliquots of serum were immediately frozen for later determination of calcium, creatinine, and iPTH.

Circadian variation. Five normal subjects and five patients with $1^{\circ} \mathrm{HPT}$ were studied. They were given $200 \mathrm{ml}$ of oral water every $2 \mathrm{~h}$ in addition to their random diet. Urine was collected at 2 -h intervals for $24 \mathrm{~h}$.

UcAMP vs. serum calcium concentrations. Eight normal subjects were studied. Their ages ranged from 39 to $58 \mathrm{yr}$ (six men and two women). They were fasted except for 200 $\mathrm{ml}$ of water/h during a 4-h control period. Hourly urine and blood specimens were collected. After collection of a baseline specimen, the serum calcium was either raised by infusing 100 or $200 \mathrm{mg}$ of calcium as calcium gluconate in 200 $\mathrm{ml}$ of $5 \%$ dextrose $/ \mathrm{h}$ or lowered by infusing $2,000 \mathrm{ml}$ of $0.9 \%$ $\mathrm{NaCl}$ over $2 \mathrm{~h}$. Calcium infusions were also done in eight patients with $1^{\circ} \mathrm{HPT}$. Base-line specimens were collected as in the normal subjects and during the $2 \mathrm{nd}$ or 4 th $\mathrm{h}$ of a $100-\mathrm{mg} / \mathrm{h}$ calcium infusion.

Laboratory methods. UcAMP was measured in duplicate using a modification (5) of the competitive protein binding assay originally described by Gilman (6). Radioimmunoassay of PTH was performed with GPIM antisera according to the method of Arnaud et al. (7). Both antiserum GPIM and reference standard were kindly supplied by Dr. C. D. Arnaud. A crude protein fraction from the medium of organ cultures of human adenomas was used as a reference standard and values are expressed as nanogram equivalents (ng eq) of this standard. The lower limit of detectability of this assay is $5 \mathrm{ng} \mathrm{eq} / \mathrm{ml}$, and the iPTH measured in normal individuals range from $<5$ to 30 $\mathrm{ng} \mathrm{eq} / \mathrm{ml}$ (5). Arnaud et al. (8) have shown that the predominate recognition site(s) for this antisera resides in the carboxylterminal (C-terminal) portion of the PTH molecule. Creatinine in serum and urine was determined by a modification of the procedure of Folin (9). Serum calcium was measured by atomic absorption spectrophotometry. Statistical analysis (Student's $t$ test and product moment correlation) was performed on a Programma 101 (Olivetti Underwood Corp., New York) using standard formulas (10).

All of the specimens in this study were analyzed within 2 mo after collection. In the frozen state, both cAMP and iPTH were found to remain stable during this time interval. Unless stated otherwise, all UcAMP concentrations are expressed as micromoles per gram of creatinine.

\section{RESULTS}

Circadian variation in UcAMP (Fig. 1). In the normal subjects, no significant circadian variation was noted in UcAMP. In the patients with $1^{\circ} \mathrm{HPT}$, no variation in UcAMP was noted during the morning or afternoon, but there was a slight fall during the early evening hours which became significant at $2000 \mathrm{~h}$ $(P<0.05)$.

1-h daylight vs. 24-h collection of urine. UcAMP in the random 1-h daylight $(0800-1800)$ collections of urine from 22 normal subjects ranged from 2.47 to 6.72 with a mean $\pm S E$ of $4.69 \pm 0.22$. UcAMP in the 24-h urine collections from 19 normal subjects ranged from 2.38 to 6.07 with a mean $\pm S E$ of $4.09 \pm 0.23$. There was no significant difference between the concentration of UcAMP in the 1-h compared to the 24-h collections in normal subjects. 


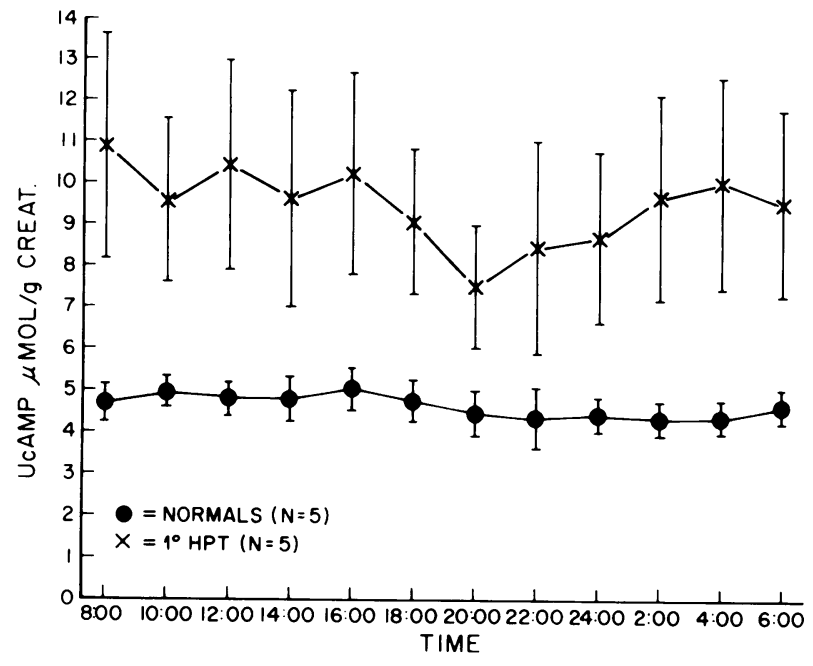

FIGURE 1 UcAMP circadian variations in normal subjects and patients with primary hyperparathyroidism. Urine was collected at 2 -h intervals for $24 \mathrm{~h}$. The brackets indicate SEM.

Both 1-h and 24-h collections of urine were obtained from 15 patients with $1^{\circ} \mathrm{HPT}$. UcAMP in the 1 -h collections ranged from 5.28 to 17.18 with a mean \pm SE of $8.98 \pm 0.86$. UcAMP in the 24 -h collections ranged from 4.13 to 17.56 with a mean \pm SE of $8.19 \pm 0.91$. There was no significant difference between the concentration of UcAMP in the 1-h compared to the 24-h collections in patients with $1^{\circ} \mathrm{HPT}$.

UcAMP in normal subjects and patients with hypercalcemia and hypocalcemia (Fig. 2). In 41 normal subjects (22 1-h and 19 24-h urine collections), the mean \pm SE UcAMP was $4.42 \pm 0.16$. In 56 patients with $1^{\circ} \mathrm{HPT}$ ( 40 1-h and 1624 -h urine collections), the mean \pm SE UcAMP was $8.48 \pm 0.43$. In 16 patients with nonparathyroid neoplasms (all 1-h collections), the mean $\pm \mathrm{SE}$ UcAMP was $8.36 \pm 1.53$. In the four patients with vitamin $\mathrm{D}$ intoxication, sarcoidosis, milk-alkali syndrome, and thiazide-induced hypercalcemia (all $1-\mathrm{h}$ urine collections), the mean $\pm \mathrm{SE}$ UcAMP was 2.90 \pm 0.24 . In the five patients with hypocalcemia due to hypoparathyroidism (all 1-h urine collections), the mean \pm SE UcAMP was $3.56 \pm 0.30$.

There was a significant difference between the UcAMP in normal subjects and those with $1^{\circ} \mathrm{HPT}$ $(P<0.001)$, but $39 \%$ of the UcAMP concentrations in the $1^{\circ} \mathrm{HPT}$ patients fell in the normal range of $2.36-$ 6.48 (mean $\pm 2 \mathrm{SD}$ ). The UcAMP in the patients with nonparathyroid neoplasms also was significantly higher than normals $(P<0.001)$, but was not significantly different from the UcAMP in patients with $1^{\circ} \mathrm{HPT}$. The UcAMP in the patients with other causes of hypercalcemia and in the patients with hypoparathyroidism was significantly lower than normal $(P<0.005$ and $P<0.05$, respectively).
The total 24-h excretion of UcAMP in 19 normal subjects ranged from 2.49 to $8.90 \mu \mathrm{mol}$ with a mean $\pm \mathrm{SE}$ of $5.49 \pm 0.38$ and in 31 patients with $1^{\circ} \mathrm{HPT}$ it ranged from 2.66 to $16.58 \mu \mathrm{mol}$ with a mean $\pm \mathrm{SE}$ of $8.38 \pm 0.69$. The mean total 24 -h excretion of UcAMP was significantly higher $(P<0.0025)$ in the patients with $1^{\circ} \mathrm{HPT}$; however, $61 \%$ of the individual values fell within the normal range.

UcAMP vs. serum calcium concentration in normal subjects (Fig. 3). There was a marginally significant negative correlation $(r=0.446, P<0.1)$ between the serum calcium concentrations and UcAMP in baseline samples obtained from eight normal subjects. Samples were obtained from these same individuals while hypocalcemic as a result of a saline infusion or hypercalcemic as a result of a calcium infusion. If samples in which serum calcium concentrations were between 8.1 and $10.5 \mathrm{mg} / \mathrm{dl}$ were included in the analysis, there was a highly significant negative correlation $(r=0.820, P<0.001)$ between the serum calcium concentration and UcAMP. When serum calcium concentrations greater than $10.5 \mathrm{mg} / \mathrm{dl}$ were obtained during calcium infusions, there was no further suppression of UcAMP. The suppression of UcAMP from a mean $\pm \mathrm{SE}$ base-line value of $5.15 \pm 0.21$ to a mean $\pm \mathrm{SE}$ of $2.99 \pm 0.13$ at serum calcium concentrations greater than $10.5 \mathrm{mg} / \mathrm{dl}$ was $41.9 \%$.

These observations in normal subjects and preliminary studies of patients with calcium disorders suggested the general scheme presented in Fig. 3.

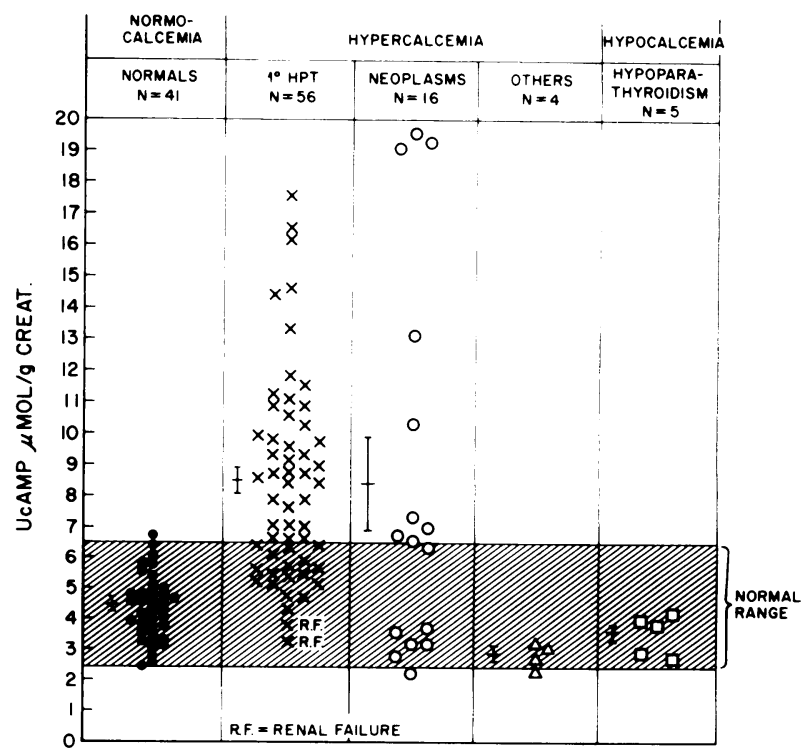

FIGURE 2 UcAMP in normal subjects compared to patients with hypercalcemia and hypocalcemia. Values include both 1-h and 24-h urine collections. The brackets indicate SEM. Values obtained in two patients with renal failure (R. F.) and serum creatinine concentrations of 4.4 and $5.3 \mathrm{mg} / \mathrm{dl}$ are indicated as R. F. 


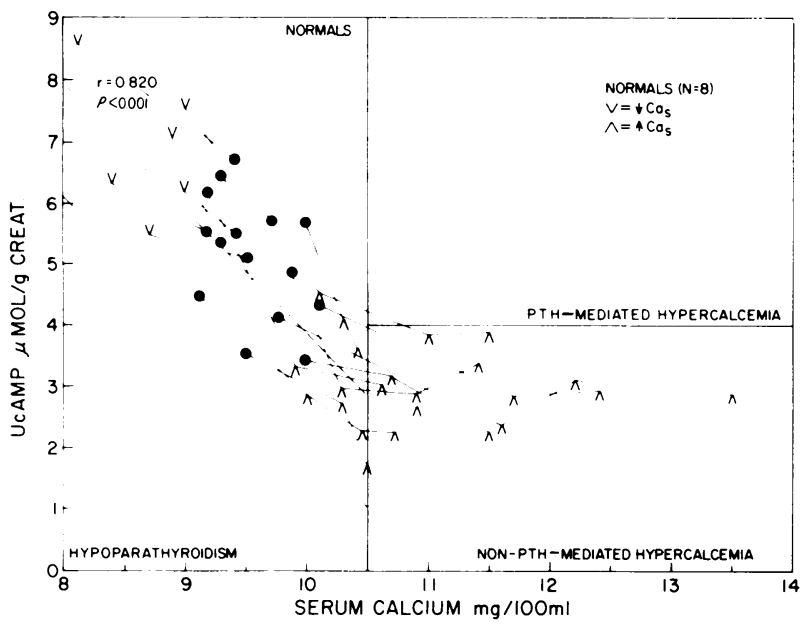

FIgURE 3 UcAMP vs. the serum calcium concentration in normal subjects during the base-line state and during induced hypercalcemia and hypocalcemia. The blocked off spaces are the areas where patients with PTH- and nonPTH-mediated hypercalcemia and those with hypoparathyroidism should fall.

That is, in hypercalcemia, a UcAMP greater than 4.0 (mean suppressed UcAMP in normal subjects $\pm 2 \mathrm{SD}$ ) is inappropriately high and indicates $\mathrm{PTH}$-mediated hypercalcemia and a UcAMP less than 4.0 is appropriate and indicates non-PTH-mediated hypercalcemia. In hypocalcemia, a UcAMP less than appropriate for the serum calcium concentration (mean UcAMP in normal subjects at the same calcium level $-2 \mathrm{SD}$ ) indicates hypoparathyroidism.

UcAMP vs. serum calcium concentration in patients with hypercalcemia and hypocalcemia (Fig. 4). The UcAMP and serum calcium concentrations in the patients studied were analyzed according to the scheme described above. Of the 56 patients with $1^{\circ} \mathrm{HPT}$, 54 of them fell into the PTH-mediated area (serum calcium concentrations greater than $10.5 \mathrm{mg} / \mathrm{dl}$ and UcAMP greater than 4.0). The two exceptions both had renal failure with serum creatinine concentrations of 4.4 and $5.3 \mathrm{mg} / \mathrm{dl}$, respectively. Calcium infusions done in eight patients with $1^{\circ} \mathrm{HPT}$ caused suppression of their UcAMP that was parallel to what was seen in normal subjects. Of the 16 patients with nonparathyroid neoplasms, 10 fell in the PTH-mediated area and 6 fell in the non-PTH-mediated area. The four other patients with hypercalcemia due to vitamin D intoxication, sarcoidosis, milk-alkali syndrome, and thiazide administration all fell in the non-PTHmediated area. The five patients with hypocalcemia due to hypoparathyroidism all fell in the predicted area. The results were the same whether $1-h$ or $24-h$ urine collections from the same subject were used for determination of UcAMP.

There was a significant positive correlation $(r$
$=0.421, P<0.01$ ) between the UcAMP and serum calcium concentration in the 54 patients with $1^{\circ} \mathrm{HPT}$ in the PTH-mediated area. No correlation was found between these indicies in the patients with non-parathyroid neoplasms in the same area.

Non-parathyroid neoplasms with hypercalcemia (Fig. 5). There was no significant difference between the mean serum calcium concentrations in the patients in the PTH- (UcAMP greater than 4.0) and non-PTH(UCAMP less than 4.0) mediated areas. The mean $\pm \mathrm{SE}$ UcAMP for all the patients with neoplasms in the PTHmediated area was $11.05 \pm 1.82$ which is significantly higher $(P<0.025)$ than for the patients with $1^{\circ} \mathrm{HPT}$. Those with adenocarcinomas had levels of UcAMP higher than those with squamous cell carcinomas. The mean \pm SE UcAMP in the patients in the nonPTH-mediated area was $3.14 \pm 0.23$. This was significantly lower $(P<0.005)$ than in the normal subjects but was not significantly different from the other hypercalcemic patients in the non-PTH-mediated area, hypoparathyroid patients, or the normal subjects whose serum calcium concentrations were above $10.5 \mathrm{mg} / \mathrm{dl}$ during calcium infusions.

6 of the 10 patients in the PTH-mediated area were submitted to a complete radiological skeletal survey and (or) Tc-99m pyrophosphate bone scan. No bone metastasis was evident. Similar studies were performed on four of the six patients in the non-PTH-mediated area. All had destructive bone lesions. Autopsies performed on two of the patients in the PTH-mediated area (lung and liver) and one patient in the non-PTH-

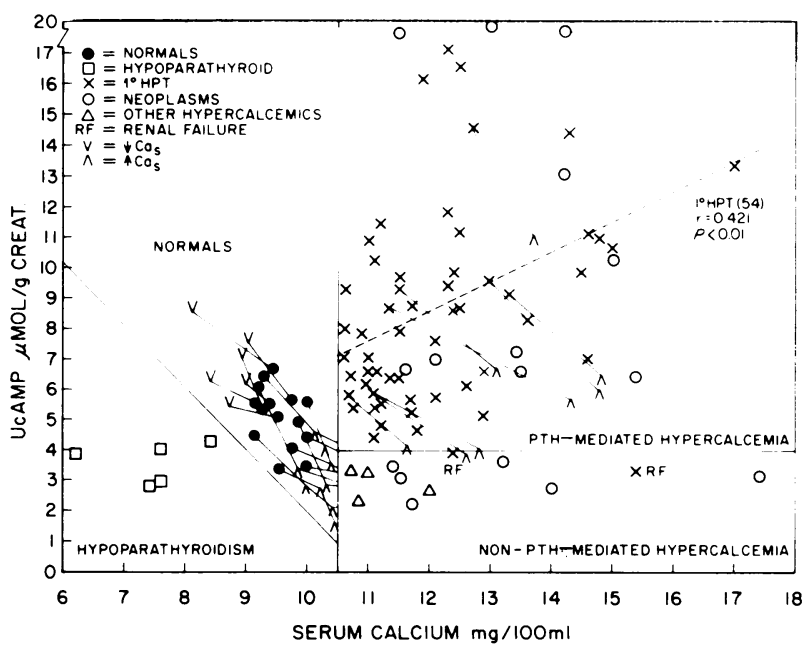

Figure 4 UcAMP vs. the serum calcium concentration in normal subjects and patients with hypercalcemia and hypocalcemia. The normal values are the same as those plotted in Fig. 3 up to a serum calcium of $10.5 \mathrm{mg} / 100 \mathrm{ml}$. The patient values are the same as those plotted in Fig. 2 plus the results of induced hypercalcemia in eight patients with $1^{\circ} \mathrm{HPT}$. 


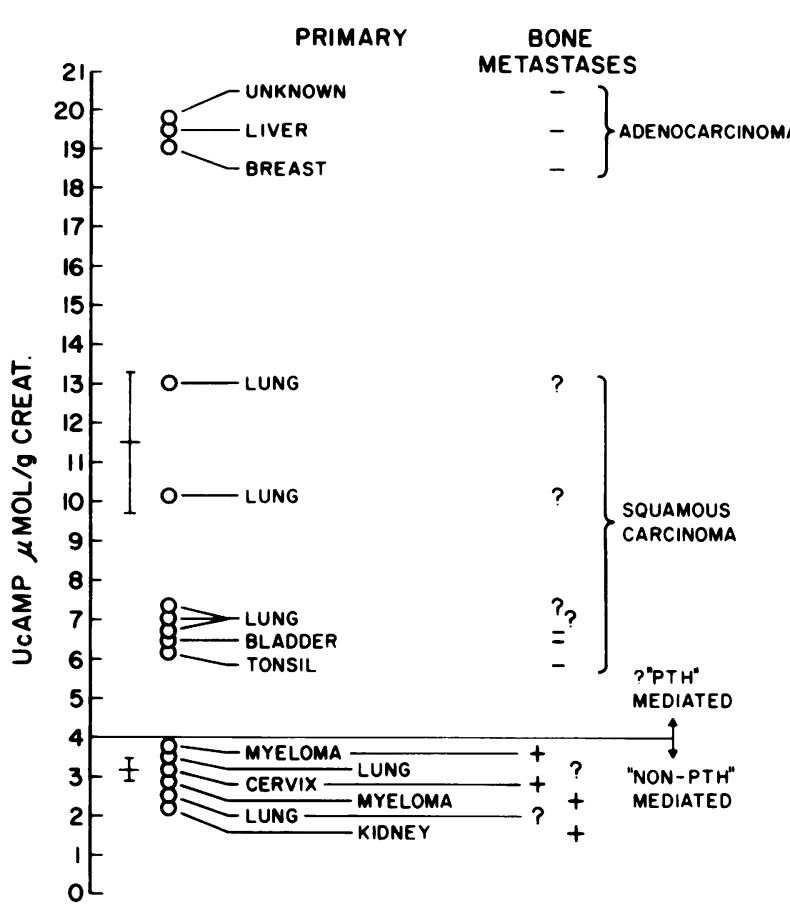

Figure 5 Analysis of the data from 16 hypercalcemia patients with nonparathyroid neoplasms with respect to UcAMP levels, type of primary tumor, and the presence or absence of bone metastasis. The brackets indicate SEM.

mediated area (lung) revealed neither parathyroid adenomas nor hyperplasia.

Serum iPTH vs. serum calcium concentration in normal subjects and patients with hyercalcemia (Fig. 6). Serum iPTH was measured in seven normal subjects (the same as in Fig. 3) in the base-line state and during alteration of their serum calcium concentrations by saline or calcium infusions. iPTH was also measured in 29 patients with $1^{\circ} \mathrm{HPT}$, including 4 who were calcium infused and 4 patients with nonparathyroid neoplasms in whom UcAMP values were in the PTH-mediated area. There was a significant negative correlation $(r=0.878, P<0.001)$ between the iPTH and the serum calcium concentrations in the normal subjects. There was a significant positive correlation $(r=0.699, P<0.001)$ between these indices in the patients with $1^{\circ} \mathrm{HPT}$ with all iPTH values being inappropriately high for the serum calcium concentrations when compared to normal subjects. In the four patients with $1^{\circ} \mathrm{HPT}$ who were calcium infused, their suppression of iPTH was parallel to that seen in normal subjects. In the four patients with nonparathyroid neoplasms, the iPTH levels were inappropriately high for their serum calcium concentrations when compard to normal subjects but were lower than in patients with $1^{\circ} \mathrm{HPT}$ with similar degrees of hypercalcemia.
Serum iPTH vs. UcAMP in normal subjects and patients with hypercalcemia (Fig. 7). There was a significant positive correlation $(r=0.756, P<0.001)$ between the serum iPTH and UcAMP in the normal subjects, but there was no correlation between these indices in the patients with $1^{\circ} \mathrm{HPT}$ or those with nonparathyroid neoplasms. Calcium infusion in four patients with $1^{\circ} \mathrm{HPT}$ did cause a decrease in UcAMP and iPTH parallel to that seen in normal subjects.

\section{DISCUSSION}

When UcAMP was expressed as micromoles per $24 \mathrm{~h}$, we noted significantly higher mean UcAMP levels in patients with $1^{\circ} \mathrm{HPT}$, but there was a $61 \%$ overlap with normal subjects. When UcAMP was expressed as micromoles per gram of creatinine to partially correct for changes in glomerular filtration rate and inaccuracies in urine collections, there was improvement in the separation between normal subjects and patients with $1^{\circ} \mathrm{HPT}$ but a $39 \%$ overlap still existed. This overlap, in general, is similar to what was found in previous studies (2-4) and limits the diagnostic usefulness of UcAMP determinations in evaluating

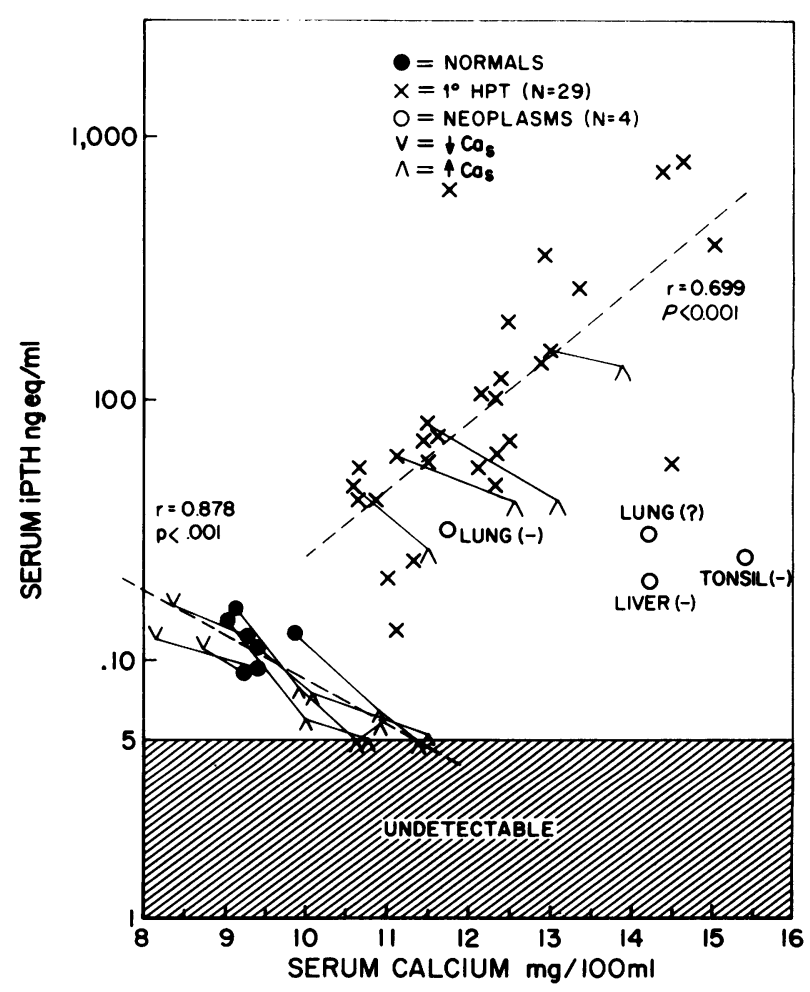

FIGURE 6 Serum iPTH vs. the serum calcium concentration in normal subjects and patients with hypercalcemia. The $(-)$ indicated the absence of bone metastasis. The units of iPTH (ng eq) refers to a crude protein fraction obtained from cultured human parathyroid adenomas. 
patients with hypercalcemia. However, when UcAMP was expressed as micromoles per gram of creatinine and analyzed as a function of the serum calcium concentration as determined in normal subjects, there was complete separation between normal subjects, patients with $1^{\circ} \mathrm{HPT}$ who had adequate renal function (serum creatinine concentrations less than $2.0 \mathrm{mg} / \mathrm{dl}$ ), patients with non-PTH-mediated hypercalcemia, and patients with hypoparathyroidism. Taylor et al. (11) have shown that subjects with azotemia have a decrease in UcAMP excretion presumably due to a decrease both in the amount filtered and the amount generated in the kidney under the control of PTH. This would explain why in our two patients with $1^{\circ} \mathrm{HPT}$ and renal failure (serum creatinine concentrations of 4.4 and $5.3 \mathrm{mg} / \mathrm{dl}$, respectively), UcAMP was not as elevated as in the other patients with $1^{\circ} \mathrm{HPT}$ and comparable concentrations of serum calcium.

Individual variations in UcAMP were noted in the normal subjects studied who were on random diets, but there was no consistent circadian variation. Although some evidence for a circadian variation in UcAMP was found in patients with $1^{\circ} \mathrm{HPT}$, there was no significant difference between the mean value of UcAMP from random 1-h day-light collections and 24-h collections. Murad and Pak (2) and Sagel et al. (12) did find a UcAMP circadian variation in normal subjects on a constant metabolic diet, with higher UcAMP levels during the daylight hours. Sagel et al. (12) were also able to correlate changes in UcAMP with the tubular resorption of phosphate. Pak et al. (13) have shown that UcAMP can be increased with oral cellulose phosphate and decreased with oral calcium and that UcAMP correlates with urinary calcium excretion in normal subjects. These findings suggest that any circadian variation in UcAMP is caused by dietary calciumand phosphate-induced alterations in the serum calcium concentration and hence PTH concentration. These results also suggest that a random UcAMP determination expressed as micromoles per gram of creatinine may be a very sensitive indicator of parathyroid gland activity.

Our results in respect to the ability to identify patients with $1^{\circ} \mathrm{HPT}$ on the basis of serum concentrations of iPTH using the C-terminal-specific antiserum of Arnaud et al. (7) are identical to his published results (14), that is a $10 \%$ overlap with normal values with complete separation when analyzed as a function of the serum calcium concentration. Our results with UcAMP expressed as micromoles per gram of creatinine are similar to the results of Arnaud et al. (8) with an amino-terminal-(N-terminal) specific PTH radioimmunoassay, that is a $40 \%$ overlap with normal values. Since it is thought that $\mathrm{N}$-terminal-specific PTH assays predominantly measure the serum concentrations of biologically active PTH (8), this adds

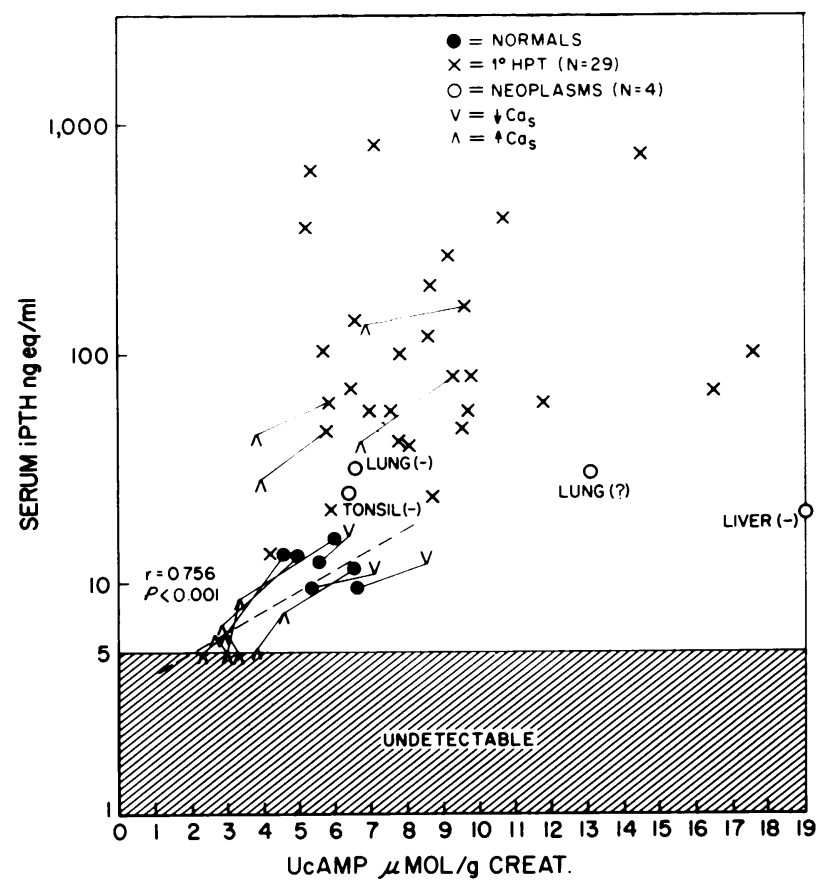

Figure 7 Serum iPTH vs. UcAMP. The same iPTH data as shown in Fig. 6 is plotted. All UcAMP measurements were made on 1 -h urine collections.

support to the idea that UcAMP is a good reflection of circulating biologically active PTH.

Significant correlations between UcAMP, serum calcium concentration, and iPTH were found in the normal subjects studied. In patients with $1^{\circ} \mathrm{HPT}$, significant correlations were noted between UcAMP and serum calcium concentration and between iPTH and serum calcium concentration, but no correlation was present between iPTH and UcAMP. Two possible explanations for this lack of correlation between iPTH and UcAMP in our patients with $1^{\circ} \mathrm{HPT}$ are as follows. The first is that many of our patients had varying degrees of renal impairment (mean creatinine clearances of $67 \mathrm{ml} / \mathrm{mins}$ ), presumably as a result of hypercalcemic nephropathy. This would tend to decrease their UcAMP (11). The second explanation is that in patients with $1^{\circ} \mathrm{HPT}$, biologically inactive fragments of $\mathrm{PTH}$ may be the major immunoreactive species of PTH measured in the serum when using a C-terminalspecific antiserum such as was used in this study (8, 15). As a result the iPTH measured would tend to overestimate the amount of biologically active PTH. These fragments can be even a greater proportion of total immunoreactivity in the serum of patients with renal failure (8). The combination of the decreased cAMP produced by the kidney and the relative increase in biologically inactive iPTH measured in the serum of patients with impaired renal function would tend to produce a splaying effect when UcAMP 
and iPTH are plotted against each other. With an $\mathrm{N}$-terminal-specific PTH radioimmunoassay, Pak et al. (13) found a significant correlation between iPTH and UcAMP in 26 patients with $1^{\circ} \mathrm{HPT}$. These findings further support the notion that UcAMP reflects biologically active circulating PTH in both normal subjects and patients with $1^{\circ} \mathrm{HPT}$.

Our patients with nonparathyroid neoplasms and hypercalcemia fell into two groups. One group, most of whom had demonstrable bone metastasis, had UcAMP levels that were indistinguishable from patients with non-PTH-mediated hypercalcemia and calcium-infused normal subjects. This suggests that the mechanism for the hypercalcemia in this group was either metastatic destruction of bone or production of an osteolytic substance other than PTH. The other group, most of whom did not have demonstrable bone metastasis, had UcAMP levels similar to patients with $1^{\circ} \mathrm{HPT}$ except that several had levels higher than any encountered in the hyperparathyroid group. This suggests that the mechanism for the hypercalcemia in this group was the ectopic production of biologically active PTH, although the presence of an accompanying parathyroid adenoma in the nonautopsied cases cannot be entirely excluded (16). Serum iPTH in four patients in this group revealed levels that were inappropriately high when compared to normal subjects but were inappropriately low when compared to patients with $1^{\circ} \mathrm{HPT}$ with similar degrees of hypercalcemia. This is similar to the data of Benson et al. (17) who were able to detect C-terminal iPTH in $95 \%$ of patients with nonparathyroid neoplasms and hypercalcemia. However, they detected iPTH with equal frequency in patients with and without bone metastasis. Our findings suggest that while most nonparathyroid neoplasms causing hypercalcemia produce PTH-like peptides that react with the C-terminal-specific assay, not all have the concomitant production of biologically active PTH-like peptides and that osteolytic factors other than PTH may be causing the hypercalcemia in such patients as has been previously suggested (18). Previous studies $(19,20)$ in patients with $1^{\circ} \mathrm{HPT}$ have shown that calcium infusions cause a suppression in both iPTH and UcAMP. Our data confirms this and also shows that patients with $1^{\circ} \mathrm{HPT}$ are equally as sensitive to changes in the serum calcium as are normal subjects up to a calcium concentration of $10.5 \mathrm{mg} / \mathrm{dl}$. We did not calcium infuse any patients with neoplasms and elevated UcAMP, but this might be a way of differentiating these patients from those with $1^{\circ} \mathrm{HPT}$.

The results from this study show that as long as there is adequate renal function (serum creatinine concentration less than $2.0 \mathrm{mg} / \mathrm{dl}$ ), a random UcAMP expressed as micromoles per gram of creatinine is a sensitive accurate reflection of circulating biologically active PTH. When analyzed as a function of the serum calcium concentration, UcAMP completely separates patients with PTH and non-PTH-mediated hypercalcemia. It does not separate patients with $1^{\circ} \mathrm{HPT}$ from patients with ectopic-PTH-producing neoplasms. However, it can be a useful adjunct to the radioimmunoassay of PTH in confirming an elevated iPTH level and in determining whether patients with neoplasms have hypercalcemia due to biologically active PTH or to other osteolytic factors.

\section{ACKNOWLEDGMENTS}

The authors wish to express their gratitude to Dr. Claude D. Arnaud for this generous gift of PTH antisera and human PTH standard, to Dr. Henry T. Keutmann for his generous gift of purified bovine PTH, to Dr. Donald E. McMillan for his assistance in doing the statistical evaluations, and to Miss Lilli Johansen and Mrs. Anne Santo for their secretarial assistance.

This work was supported, in part, by U.S. Public Health Service Training grant AM 05176 and General Clinical Research Center grant RR-43.

\section{REFERENCES}

1. Kaminsky, N. I., A. E. Broadus, J. G. Hardman, D. J. Jones, Jr., J. H. Ball, E. W. Sutherland, and G. W. Liddle. 1970. Effects of parathyroid hormone on plasma and urinary adenosine $3^{\prime}, 5^{\prime}$-monophosphate in man. J. Clin. Invest. 49: 2387-2395.

2. Murad, F., and C. Y. C. Pak. 1972. Urinary excretion of adenosine $3^{\prime}, 5^{\prime}$-monophosphate and guanosine $3^{\prime}, 5^{\prime}$ monophosphate. N Engl. J. Med. 286: 1382-1387.

3. Dohan, P. H., K. Yamashita, P. R. Larsen, B. Davis, L. Deftos, and J. B. Field. 1972. Evaluation of urinary cyclic $3^{\prime}, 5^{\prime}$-adenosine monophosphate excretion in the differential diagnosis of hypercalcemia. J. Clin. Endocrinol. Metab. 35: 775-784.

4. Neelon, F. A., M. Drezner, B. M. Birch, and H. E. Lebovitz. 1973. Urinary cyclic adenosine monophosphate as an aid in the diagnosis of hyperparathyroidism. Lancet. I: $631-633$.

5. Shaw, J. W., S. B. Oldham, J. E. Bethune, and M. P. Fichman. 1974. Parathyroid hormone (PTH)-mediated rise in urinary cyclic AMP (UcAMP) during acute extracellular fluid (ECF) expansion natriuresis in man. J. Clin. Endocrinol. Metab. 39: 311-315.

6. Gilman, A. G. 1970. A protein binding assay for adenosine 3',5'-cyclic monophosphate. Proc. Natl. Acad. Sci. U.S.A. 67: 305-312.

7. Arnaud, C. D., H. S. Tsao, and T. Littledike. 1971. Radioimmunoassay of human parathyroid hormone in serum. J. Clin. Invest. 50: 21-34.

8. Arnaud, C. D., R. S. Goldsmith, P. J. Bordier, G. W. Sizemore, J. A. Larsen, and J. Gilkinson. 1974. Influence of immunoheterogeneity of circulating parathyroid hormone on results of radioimmunoassays of serum in man. Am. J. Med. 56: 785-793.

9. Folin, O. 1914. On the determination of creatine and creatine in urine. J. Biol. Chem. 17: 469-473.

10. Colton, T. 1974. Statistics in Medicine. Little, Brown and Co., Boston, Mass. 127-131, 209-214.

11. Taylor, A. L., B. B. Davis, L. G. Pawlson, J. B. Josimovich, and D. H. Mintz. 1970. Factors influencing the 
urinary excretion of $3^{\prime}, 5^{\prime}$-adenosine monophosphate in humans. J. Clin. Endocrinol. Metab. 30: 316-324.

12. Sagel, J., J. A. Colwell, C. B. Loadholt, and G. Lizarralde, 1973. Circadian rhythm in the urinary excretion of cyclic 3',5'-adenosine monophosphate in man. J. Clin. Endocrinol. Metab. 37: 570-573.

13. Pak, C. Y. C., M. Ohata, E. C. Lawrence, and W. Snyder. 1974. The hypercalciurias. Causes, parathyroid functions, and diagnostic criteria. J. Clin. Invest. 54: 387-400.

14. Arnaud, C. D., F. P. DiBella, H. B. Brewer, K. Zawistowski, and J. Verheyden. 1974. Human parathyroid hormone: biologic and immunologic activities of its synthetic (1-34) tetratriacontrapeptide and the utility of a carboxylterminal-specific radioimmunoassay in assessment of hyperparathyroid syndromes. Calcium-regulating hormones. Excerpta Med. Int. Congr. Ser. 346: 15-22.

15. Segre, G. V., J. F. Habener, D. Powell, G. W. Tregear, and J. T. Potts, Jr. 1972. Parathyroid hormone in human plasma: immunochemical characterization and biological implications. J. Clin. Invest. 51: 3163-3172.
16. Kaplan, L., A. D. Katz, C. Ben-Isaac, and S. G. Massry. 1971. Malignant neoplasms and parathyroid adenoma. Cancer (Phila.). 28: 401-407.

17. Benson, R. C., Jr., B. L. Riggs, B. M. Pickard, and C. D. Arnaud. 1974. Radioimmunoassay of parathyroid hormone in hypercalcemic patients with malignant disease. Am. J. Med. 56: 821-826.

18. Powell, D., F. R. Singer, T. M. Murray, C. Minkin, and J. T. Potts, Jr. 1973. Nonparathyroid humoral hypercalcemia in patients with neoplastic diseases. N. Engl. J. Med. 289: 176-181.

19. Potts, J. T., Jr., T. M. Murray, M. Peacock, H. D. Niall, G. W. Tregear, H. T. Keutmann, D. Powell and L. J. Deftos. 1971. Parathyroid hormone: sequence, synthesis, immunoassay studies. Am. J. Med. 50: 639-649

20. Wray, H. L., R. L. Atkinson, Jr., J. C. Low, M. Schaaf, and J. M. Earll. 1973. Evidence for non-autonomy of biologically active parathyroid hormone in diseases of calcium metabolism. Clin. Res. 21: 642. (Abstr.) 